\title{
scripted
}

Volume 13, Issue 2, August 2016

\section{A PrinCiPled APPROACH To NeTWORK NEUTRALITY}

\author{
Lucie C. Audibert and Andrew D. Murray*
}

\begin{abstract}
The issue of regulation for mandated network neutrality is currently live in both the United States and the European Union. Traditionally, the models applied have been of the command and control or market regulation variety. Both approaches have been extensively criticised and both have suffered setbacks in recent years. This paper suggests it is time to abandon our experiments with traditional business regulation models and move to a principled approach for network neutrality. This principled approach, based upon the rights to privacy, expression and freedom to carry on a business, identifies the Internet as a public good which requires to be protected from interference if we are to fully realise its democratic potential. The proposed principled, or rights-based, approach to net neutrality would see regulations for network neutrality based in principles of fundamental rights and not business or market regulation principles. We believe this would be a radical new model for network neutrality regulation.
\end{abstract}

DOI: $10.2966 /$ scrip. 130216.118

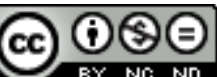

EY No No (C) Lucie C. Audibert and Andrew D. Murray 2016. This work is licensed under a Creative Commons Licence. Please click on the link to read the terms and conditions.

\footnotetext{
* Department of Law, London School of Economics.
} 


\section{Introduction}

The Internet is much more than a platform to post pictures of cute cats and silly videos. It has vital democratic and cultural functions ${ }^{1}$ and should be considered a public good to which open and free access is a fundamental right. ${ }^{2}$ The development of technologies such as intelligent routers and smart protocols, however, have led to telecommunications companies developing the capacity to manage their network for quality of service (QoS) purposes. The customer has driven much of the demand for this. As we make greater and more intensive demands upon our digital telecommunications network, the operators of that network have been driven by QoS requirements. The extensive demand that high definition video on demand (VoD) makes on network capacity ${ }^{3}$ has led to tussles between Netflix, the leading provider of such content, and some network providers. ${ }^{4}$ In addition greater demand for services with little latency tolerance such as Voice over Internet Protocol (VoIP) put pressure on telecommunications providers to offer high QoS. ${ }^{5}$ As Pujolle and Gaïti observe:

As user needs are becoming increasingly various, demanding and customised, IP networks and more generally telecommunication networks have to evolve in order to satisfy these requirements. That is, a network has to integrate more quality of service, mobility, dynamicity, service adaptation, etc. This evolution will make users satisfied, but it will surely create more complexity in the network generating difficulties in the control process. ${ }^{6}$

Such QoS systems run counter to the core network principle of end-to-end communications, whereby the intelligence of the network lies only at the two ends of a particular communication, rather than in the route it takes to get from one end to the

\footnotetext{
1 On the democratic function of the Internet, see E Laidlaw, Regulating Speech in Cyberspace Gatekeepers, Human Rights and Corporate Responsibility (Cambridge: CUP, 2015); L Dahlberg and E Siapera (eds) Radical Democracy and the Internet: Interrogating Theory and Practice (London: MacMillan, 2007). On the Internet and culture, see $\mathrm{T}$ Streeter, The Net Effect: Romanticism, Capitalism, and the Internet (New York: NYU Press, 2010); B Danet and SC Herring (eds) The Multilingual Internet: Language, Culture, and Communication Online (Oxford: OUP, 2007).

${ }^{2}$ See Laidlaw, ibid. See also N Lucchi, “Access to Network Services and Protection of Constitutional Rights: Recognizing the Essential Role of Internet Access for the Freedom of Expression" (2011) 19 Cardozo Journal of International and Comparative Law 645.

3 According to data analysts Sandline, Netflix accounted for $36.5 \%$ of all downstream Internet bandwidth during peak periods in North America for March 2015. In same time period, YouTube accounted for $15.6 \%$ of downstream Internet traffic, web browsing was 6\%, Facebook was $2.7 \%$, Amazon Instant Video was $2.0 \%$ and Hulu was $1.9 \%$. See T Spangler, "Netflix Bandwidth Usage Climbs to Nearly 37\% of Internet Traffic at Peak Hours" (Variety 28 May 2015).

${ }^{4}$ Netflix Media Center, "Netflix Applauds Appeals Court Ruling on Net Neutrality" (14 June 2016) available at https://media.netflix.com/en/press-releases/netflix-applauds-appeals-court-ruling-on-netneutrality (accessed 12 Aug 16); J Brodkin, "Cable group: Net neutrality rules for Netflix! (But not for us)" (Ars Technica, 28 March 2016) available at http://arstechnica.com/business/2016/03/cable-groupnet-neutrality-rules-for-netflix-but-not-for-us/ (accessed 12 Aug 16).
}

${ }^{5}$ K Gonia, SANS Institute Reading Room, “Latency and QoS for Voice over IP” (2004) available at https://www.sans.org/reading-room/whitepapers/voip/latency-qos-voice-ip-1349 (accessed 12 Aug 16).

${ }^{6}$ G Pujolle and D Gaït, "Intelligent Routers and Smart Protocols" in FA Aagesen, C Anutariya and V Wuwongse (eds) Intelligence in Communications Systems (London: Springer, 1998). 
other. ${ }^{7}$ This concept has become embedded into the cultural and then legal concept of 'net neutrality', which dictates that "data packets on the Internet should be moved impartially, without regard to content, destination or source", 8 and so risk endangering the open character of the Internet.

Against this backdrop, mandating network neutrality through regulation is seen as crucial to the protection of fundamental human rights and to ensure fair competition and innovation. Proponents of such regulation argue that it promotes freedom and enhances network access. ${ }^{9}$ Although there are many, especially in the telecommunications industry, who continue to question the value of mandated network neutrality, the mainstream literature in regulation and governance has moved towards its acceptance. ${ }^{10}$ The question is no longer should we regulate to protect net neutrality, but how should we do it? This paper proposes a new approach, one which departs from the institutionalist command and control, and competition-based approaches, which up to this point have been the dominant models, applied in the United States and the European Union. We recommend a new model: a principled approach. Before then though we begin by examining the current institutionalist approaches.

\section{The Institutionalist Approach to Net Neutrality}

The net neutrality debate began in the United States when high-profile proponents of mandated network neutrality, including Professor Lawrence Lessig, Professor Sir Tim Berners-Lee, Professor Tim Wu, and Craigslist founder Craig Newmark supported a proposal for a federal net neutrality law. ${ }^{11}$ This movement met some degree of success when, in 2006, Senators Byron Dorgan and Olympia Snowe introduced the Internet Freedom Preservation Bill (or Dorgan-Snowe Bill) ${ }^{12}$ which sought to legally enshrine the principle of net neutrality. The Bill though quickly became bogged down amid claims from the telecommunications industry that Dorgan-Snowe was disproportionate as there was no evidence that industry self-regulation was failing, that its effect would be to protect Internet giants like Microsoft, Google, Yahoo! and eBay rather than their customers and that it would deter investment by telecoms companies in high-speed data networks as they would not be able to recover their costs. The Bill fizzled out in summer 2006 when it failed to clear a congressional

7 JH Saltzer, DP Reed and DD Clark, "End-to-end arguments in system design" (1984) 2 ACM Transactions on Computer Systems 277-288.

${ }^{8}$ A Murray, Information Technology Law: The Law and Society 3ed, (Oxford: OUP, 2016) 26.

${ }^{9} \mathrm{~T} \mathrm{Wu}$, "Network Neutrality, Broadband Discrimination", (2003) 2 Journal of Telecommunications and High Technology Law 141-179.

${ }^{10}$ C Marsden, Net Neutrality (Bloomsbury, London 2010); T Wu, The Master Switch (London: Atlantic, 2012); L Belli and P De Filippi (eds) Net Neutrality Compendium: Human Rights, Free Competition and the Future of the Internet (London: Springer, 2015).

${ }^{11}$ T Wu and L Lessig, "Ex Parte Submission in CS Docket No. 02-52" (22 August 2003) available at http://www.savetheinternet.com/sites/default/files/resources/wu lessig fcc.pdf (accessed 12 Aug 16); T Berners-Lee, "Net Neutrality: This is serious" (21 June 2006) available at http://dig.csail.mit.edu/breadcrumbs/node/144; C Newmark, "Keep the Internet neutral, fair and free" \begin{tabular}{lllll}
\hline$C N N$, & 20 & October & $2006)$ & available
\end{tabular} http://edition.cnn.com/2006/US/06/09/newmark.internet/index.html (accessed 12 Aug 16).

${ }^{12}$ S 215. 
vote, a fate that also befell the Internet Freedom Preservation Bill of 2008. ${ }^{13}$ Undeterred, the campaigners continued to press for action.

\section{1. Command and Control}

In 2007, it became apparent that one of the giant US cable companies, Comcast, was interfering with the ability of their cable modem customers to access BitTorrent services by resetting services that used BitTorrent packets. They were doing this as a traffic management tool to prevent BitTorrent using up all available upstream bandwidth to the detriment of other customers. They were referred to the Federal Communications Commission (FCC) by two public advocacy groups, Free Press and Public Knowledge. The complaint stated that Comcast's actions violated the FCC Internet Policy Statement, particularly violating the statement's principle that "consumers are entitled to access the lawful Internet content of their choice ... [and] to run applications and use services of their choice". Comcast defended its interference as necessary intervention to manage scarce network capacity. In August 2008 the FCC published the results of its investigation. They found that Comcast's bandwidth management methods contravened federal policy by "significantly impeding consumers' ability to access the content and use the applications of their choice". ${ }^{14}$ By the time the order was issued, Comcast had adopted new management methods and, as a result, the order effectively only required Comcast to disclose the details of those new methods and their implementation. Comcast agreed to comply with the order but also filed for review in the District of Columbia Circuit of the US Court of Appeals, claiming (among other things) that the FCC did not have jurisdiction over its network management methods.

Buoyed by their initial success in regulating Comcast, the FCC decided to seek public input on a new set of draft rules that would codify and supplement existing principles to safeguard Internet openness. After holding a series of reviews and public meetings, the FCC adopted the Open Internet Report and Order in December $2010 .{ }^{15}$ The order, which took effect on 20 November 2011, established three basic open Internet rules designed to preserve the free and open Internet. These are: (1) Transparencybroadband providers must disclose information regarding their network management practices, performance and the commercial terms of their broadband services; (2) No blocking - fixed broadband providers (such as DSL, cable modem or fixed wireless providers) may not block lawful content, applications, services or non-harmful devices, and mobile broadband providers may not block lawful websites, or applications that compete with their voice or video telephony services; and (3) No unreasonable discrimination-fixed broadband providers may not unreasonably discriminate in transmitting lawful network traffic over a consumer's broadband Internet access service. Unreasonable discrimination of network traffic could take the form of particular services or websites appearing slower or degraded in quality.

\footnotetext{
${ }^{13}$ HR 3458.

${ }^{14}$ In re Formal Complaint of Free Press \& Public Knowledge Against Comcast Corporation for Secretly Degrading Peer-to-Peer Applications 23 FCCR 13,028 at 13,054 (2008).

${ }^{15}$ Federal Communications Commission, "Preserving the Open Internet; Final Rule" 76 (185) Federal Register 59192 (2011).
} 
While the FCC had been busy doing this the appeal in Comcast had been heard by the United States Court of Appeals for the District of Columbia. In April 2010, the court vacated the FCC's order, holding that the FCC had no authority over Comcast's Internet service because "the Commission had failed to tie its assertion of ancillary authority over Comcast's Internet service to any 'statutorily mandated responsibility". ${ }^{16}$ In essence, the FCC had been found to have acted ultra vires as they had no mandate or authority to interfere with network management capability as such interference was not ancillary to their primary statutory role. This decision suggests that any attempt to actually enforce the Open Internet Report and Order would be fruitless as applying Comcast, the FCC have no authority to intervene in network and traffic management. If this were true, the Open Internet Report and Order becomes merely a guideline, not an order; however, things are not so clear-cut. It has been noted by one commentator that "the impact of this decision on the FCC's ability to regulate broadband services and implement its broadband policy goals remains unclear" 17 while the then FCC Chairman Julius Genachowski commented in April 2010: "The court decision earlier this week does not change our broadband policy goals, or the ultimate authority of the FCC to act to achieve those goals. The court did not question the FCC's goals; it merely invalidated one technical, legal mechanism for broadband policy chosen by prior Commissions." 18 The Chairman made this statement while announcing the next stage of the FCC's broadband, including net neutrality, policy which included the adoption of the Open Internet Order. As may therefore have been expected, the efficacy of the Open Internet Report and Order was immediately challenged by a number of telecommunications companies, including Verizon and MetroPCS. ${ }^{19}$ All these challenges were eventually consolidated into a single review before the US Court of Appeals for the Circuit of the District of Columbia. ${ }^{20}$ In the consolidated action, the telecommunications companies argued that the Comcast decision rendered the FCC Open Internet Order ultra vires and in the alternative that it interfered with their First Amendment rights.

The Court issued its ruling in January $2014 .^{21}$ The Court began by framing its terms of reference: "our task as a reviewing court is not to assess the wisdom of the Open Internet Order regulations, but rather to determine whether the Commission has demonstrated that the regulations fall within the scope of its statutory grant of authority." 22 The Court then broke the Order up into its constituent parts and either vacated or upheld each part. Applying Comcast (among other authorities) the Court found that an earlier decision of the FCC to classify broadband providers as

\footnotetext{
${ }^{16}$ Comcast Corp. v FCC, 600 F 3d 642, 661 (2010).

17 AA Gilroy, Access to Broadband Networks: The Net Neutrality Debate Congressional Research Service R40616, 4 (16 April 2015). Available at www.fas.org/sgp/crs/misc/R40616.pdf (accessed 12 Aug 16.

18 FCC, FCC Announces Broadband Action Agenda (8 April 2010). Available at http://hraunfoss.fcc.gov/edocs_public/attachmatch/DOC-297402A1.pdf (accessed 12 Aug 16).
}

\footnotetext{
${ }^{19}$ Verizon v. FCC, Case No. 11-1014 (D.C. Cir. January 20, 2011); MetroPCS Communications et al. v. FCC, Case No. 11-1016 (D.C. Cir. January 24, 2011).

${ }^{20}$ Verizon Communications Inc. v. FCC 740 F.3d 623 (D.C. Cir. 2014).

${ }^{21}$ Ibid.

${ }^{22}$ Ibid, 17.
} 
"information services" and not "telecommunication services" meant that broadband service providers were not subject to so-called common carrier regulation under Title II of the Communications Act $1934 .{ }^{23}$ The effect of this was to render invalid the provisions of the Open Internet Order on anti-discrimination and anti-blocking as "the Commission has failed to establish that the anti-discrimination and anti-blocking rules do not impose per se common carrier obligations." ${ }^{24}$ The decision to vacate the key anti-blocking and anti-discrimination provisions gutted the Open Internet Order of its capacity to enshrine and protect net neutrality, leaving only the provision on transparency, but brought about quite unexpected consequences and the next round of attempts to enshrine net neutrality through regulation in the United States.

While the telecommunications companies reacted positively to the outcome of the case by making announcements that they would not seek to interfere with the customer Internet experience provided by an open Internet, ${ }^{25}$ pressure was quickly brought to bear on the US Federal government by free Internet advocates. A petition was launched on the White House petitions site calling upon the Obama administration to "Restore Net Neutrality By Directing the FCC to Classify Internet Providers as "Common Carriers"'. It quickly received over 105,000 signatures. ${ }^{26} \mathrm{In}$ response, the White House replied that "preserving an open Internet is vital not just to the free flow of information, but also to promoting innovation and economic productivity", but cautioned that "the FCC is an independent agency" and therefore the President was not able to mandate the FCC to take any action. ${ }^{27}$

While the petition was open for signatures, the new FCC Chairman Tom Wheeler issued a statement responding to the Verizon decision. In this he stated that the FCC would not appeal the decision, but instead would establish new rules for transparency, non-discrimination, and anti-blocking, based on the decision. ${ }^{28}$ With the petition quickly gathering signatories, the White House became fully engaged. Despite the fact that the President had no power to mandate the FCC, he leveraged political pressure when he made a statement calling upon the FCC to "implement the strongest possible rules to protect net neutrality" and setting out four bright line rules which he suggested "reflect the Internet you and I use every day, and that some ISPs already observe": no blocking, no throttling, increased transparency, and no paid prioritization. ${ }^{29}$ On 26 February 2015 the FCC issued a new 2015 Open Internet Rules

\footnotetext{
${ }^{23}$ Ibid, 9.

${ }^{24}$ Ibid per Tatel CJ at 4.

25 J Lowensohn, "Comcast, Verizon, and others promise net neutrality ruling won't hurt customers" (The Verge, 14 January 2014) Available at www.theverge.com/2014/1/14/5309268/comcast-verizonand-others-promise-net-neutrality-ruling-wont-hurt (accessed 12 Aug 16).

26 (15 January 2014) available at https://petitions.whitehouse.gov/petition/restore-net-neutralitydirecting-fcc-classify-internet-providers-common-carriers (accessed 12 Aug 16).

${ }^{27}$ Ibid.

${ }^{28}$ FCC, Statement by FCC Chairman Tom Wheeler on the FCC's Open Internet Rules (19 February 2014). Available at www.fcc.gov/document/statement-fcc-chairman-tom-wheeler-fccs-open-internetrules (accessed 12 Aug 16).

${ }^{29}$ White House, Net Neutrality: President Obama's Plan for a Free and Open Internet (10 November 2014). Available at www.whitehouse.gov/net-neutrality (accessed 12 Aug 16).
} 
and Order. ${ }^{30}$ The order firstly deals with the Verizon decision by reclassifying broadband Internet access service as a telecommunications service under Title II of the Communications Act of $1934 .^{31}$ The Commission justify this, not only as a response to Verizon but because "our reclassification of the broadband Internet access service means that we can regulate, consistent with the Communications Act, broadband providers to the extent they are 'engaged' in providing the broadband Internet access service." 32 In essence the argument made by the Commission is that in the modern world consumers see broadband providers as being similar to telecommunications providers of old; common carriers who are responsible for carrying and delivering our Internet content from point to point. While this may not be technically true (the moment our email leaves our ISPs servers anyone can be carrying it by any route) it is how broadband providers advertise themselves by promoting download (and to a lesser extent upload) speeds and network security. Thus, as far as the consumer is concerned, their broadband provider is the party responsible for delivering their email and making sure they can get access to Netflix. As the Commission notes:

The representation to retail customers that they will be able to reach "all or substantially all Internet endpoints" necessarily includes the promise to make the interconnection arrangements necessary to allow that access. As a telecommunications service, broadband Internet access service implicitly includes an assertion that the broadband provider will make just and reasonable efforts to transmit and deliver its customers' traffic to and from "all or substantially all Internet endpoints" under sections 201 and 202 of the Act . .. Thus, disputes involving a provider of broadband Internet access service regarding Internet traffic exchange arrangements that interfere with the delivery of a broadband Internet access service end user's traffic are subject to our authority under Title II of the Act. ${ }^{33}$

Having secured a reason to regulate broadband providers under Title II the Order sets out a new 2015 series of bright line rules, based upon President Obama's statement: (1) No blocking-A person engaged in the provision of broadband Internet access service, insofar as such person is so engaged, shall not block lawful content, applications, services, or non-harmful devices, subject to reasonable network management; (2) No throttling-A person engaged in the provision of broadband Internet access service, insofar as such person is so engaged, shall not impair or degrade lawful Internet traffic on the basis of Internet content, application, or service, or use of a non-harmful device, subject to reasonable network management; (3) No Paid prioritization-A person engaged in the provision of broadband Internet access service, insofar as such person is so engaged, shall not engage in paid prioritization; and (4) No unreasonable interference or unreasonable disadvantage standard for Internet conduct - Any person engaged in the provision of broadband Internet access

\footnotetext{
${ }^{30}$ FCC15-24: https://apps.fcc.gov/edocs_public/attachmatch/FCC-15-24A1.pdf (accessed 12 Aug 16).

31 Ibid, 59.

32 Ibid, 339.

${ }^{33}$ Ibid, 204.
} 
service, insofar as such person is so engaged, shall not unreasonably interfere with or unreasonably disadvantage (i) end users' ability to select, access, and use broadband Internet access service or the lawful Internet content, applications, services, or devices of their choice, or (ii) edge providers' ability to make lawful content, applications, services, or devices available to end users. Reasonable network management shall not be considered a violation of this rule. ${ }^{34}$ In addition to the four basic open Internet rules found in the 2015 Rules, it should be remembered that the transparency provision of the 2010 rules remains in effect giving us five basic open Internet rules in total. ${ }^{35}$

The rules took effect on 12 June 2015 but as may be expected, before they took effect, they were challenged by broadband providers. A petition was filed by the United States Telecom Association (USTA) claiming that:

Broadband Internet access fits squarely within the 1996 [Telecommunications] Act's definition of "information service[s]," 47 U.S.C. $§ 153(24)$, that may not be regulated as common carriage under Title II. And Congress explicitly stated that the term "information service" "includ[es] specifically a service . . . that provides access to the Internet." $\S 230(\mathrm{f})(2)$ ' and that the FCC has tried 'to evade [the] Court's holding in Verizon. ${ }^{36}$

The claim goes on to suggest that the whole action of the FCC is illegal as well as substantively invalid:

The Order is independently unlawful because the FCC - in its headlong rush to implement this regulatory sea change at the President's urging committed a string of glow-in-the-dark [Administrative Procedure Act] violations, any one of which would suffice to invalidate the Order. The FCC's original proposal to adopt a handful of prophylactic rules gave no notice that the FCC intended to craft out of whole cloth a "Title II tailored for the $21 \mathrm{st}$ Century", to rewrite its rules concerning mobile services, to redefine fundamentally the broadband service that it reclassified, or to adopt an amorphous "Standard for Internet Conduct", which gives the agency unfettered discretion to regulate new and innovative offerings. And the FCC abandoned its own longstanding classification decisions without grappling with either its prior legal conclusions and factual findings or the billions of dollars invested in reliance on prior policy. ${ }^{37}$

\footnotetext{
${ }^{34}$ Ibid, 15-22.

35 Ibid, 23- 24.

${ }^{36}$ United States Telecom Association v FCC \& Ors. CA D.C. Filed13/5/2015, 2. Available at www.publicknowledge.org/assets/uploads/blog/15.05.13_Motion_for_Stay.pdf (accessed 12 Aug 16).

${ }^{37}$ Ibid, 3 .
} 
Recently, the Court of Appeals for the District of Columbia reviewed the legality of the Order. ${ }^{38}$ In a controversial decision, and by a 2-1 majority, the Court upheld the order in full finding that the FCC had the proper authority to reclassify broadband Internet under the Title II. In their controversial opinion the Court stated that:

The problem in Verizon was not that the Commission had misclassified the service between carriers and edge providers but that the Commission had failed to classify broadband service as a Title II service at all. The Commission overcame this problem in the Order by reclassifying broadband service - and the interconnection arrangements necessary to provide it — as a telecommunications service. ${ }^{39}$

While campaigners in favour of mandated net neutrality have welcomed the decision, ${ }^{40}$ opponents of the Order have pointed out that the Court appeared to have developed a circular argument without resolution by finding that "the FCC's rules prohibit internet providers from deciding what content they are willing to publish or distribute - an 'invasion of a legally protected interest' that implicates internet service providers' First Amendment rights" while holding that "this abridgment of internet providers' First Amendment rights is permissible." ${ }^{41}$ It seems highly likely that for this reason alone this case will be appealed to the Supreme Court and therefore we cannot yet treat the issue as settled in the United States.

\section{2. Market Regulation}

The issue of mandated network neutrality is not only an American one. The issue is equally economically important, although until recently arguably less politicised, in Europe. One of the reasons the issue was less political was a greater array of consumer choice on the European market for Internet access. In the US, fixed-line broadband access was, and is, most commonly achieved via a cable provider. This means that for many subscribers they have a limited choice of perhaps only two or three (or even one) Internet access providers. In the EU most people got, and still get, their fixed-line access over digital subscriber lines or DSL (more commonly known as telephone lines). This means that the average European consumer has a choice of several access providers. In the UK, for example, Ofcom lists over fifty competing fixed-line service providers, ${ }^{42}$ although admittedly most home users get their home broadband access from the 'big five' providers: BT/PlusNet, Sky Broadband, Virgin

\footnotetext{
${ }^{38}$ United States Telecom Association v FCC \& Ors. CA D.C. No. 15-1063, 14 June 2016. Available at https://www.cadc.uscourts.gov/internet/opinions.nsf/3F95E49183E6F8AF85257FD200505A3A/\%24fil e/15-1063-1619173.pdf (accessed 12 Aug 16).

${ }^{39}$ Ibid, 54-55.

${ }^{40}$ C. Kang, "Court Backs Rules Treating Internet as Utility, Not Luxury" (The New York Times, 14 June 2016). Available at http://www.nytimes.com/2016/06/15/technology/net-neutrality-fcc-appealscourt-ruling.html (accessed 12 Aug 16).

${ }^{41}$ F. Campbell, “Court's Net Neutrality Opinion Wrong About First Amendment” (Forbes, 22 July 2016). Available at http://www.forbes.com/sites/fredcampbell/2016/07/22/courts-net-neutralityopinion-wrong-about-first-amendment/ (accessed 12 Aug 16).

42 Ofcom, "List of ISP Signatories to the 2010 Code" available at http://stakeholders.ofcom.org.uk/telecoms/codes-of-practice/broadband-speeds-cop-2010/list-of-isps$\underline{2010}$ (accessed 12 Aug 16)
} 
Media, TalkTalk, and EE. ${ }^{43}$ The end-user can change their ISP simply by requesting their new provider to change the service over to them. ${ }^{44}$ Until recently, the prevailing theory within Europe was that with greater competition in the Internet access market, and with the regulatory authority ready to intervene should one of the behemoths of the Internet access market decide to interfere with the quality of service of its customers, there was no need for proscriptive regulatory intervention.

In Europe, as in the US, institutional regulation has to date been employed to protect net neutrality. However, as the role of markets was more pronounced, it has traditionally taken a different form. Whereas the US model was direct regulation through command and control, as evidenced by the 2010 and 2015 Rules and the extensive litigation surrounding them, the European model was through a hybrid of self-regulation and competition regulation. This can most clearly be seen in Ofcom's Net Neutrality Statement of 24 November 2011 where it was noted that "to date, the market has generally been an effective mechanism for delivering the benefits described above. Our approach to traffic management will therefore continue to rely primarily on there being effective competition amongst Internet Service Providers. $" 45$

These two competing regulatory models, Command and Control and Competition remain at the heart of the institutionalist approach to net neutrality. More recently, however, Europe's reliance on competition regulation has seemed less secure. As we moved from traditional DSL lines to fibre-optic access the market narrowed. As a result European nations began to take steps to secure net neutrality through legal mandate. On 29 September 2010 a ministerial declaration from the Council of Europe stated that:

Users should have the greatest possible access to Internet-based content, applications and services of their choice, whether or not they are offered free of charge, using suitable devices of their choice. Such a general principle, commonly referred to as network neutrality, should apply irrespective of the infrastructure or the network used for Internet connectivity. ${ }^{46}$

It then went on to acknowledge that although

Operators of electronic communication networks may have to manage Internet traffic [and] this management may relate to quality of service, the development of new services, network stability and resilience or combating

\footnotetext{
${ }^{43}$ The proposed merger of BT and EE will reduce this further to a 'big four'. See 'Final Report of the Competition and Markets Authority on the anticipated acquisition by BT Group plc. of EE Limited' (16 January 2016). Available at https://assets.digital.cabinetoffice.gov.uk/media/56992242ed915d4747000026/BT_EE_final_report.pdf (accessed 12 Aug 16).

44 Ofcom, "Switching Broadband available at http://consumers.ofcom.org.uk/internet/broadband-switching/switching-broadband-provider/ (accessed 12 Aug 16).

45 Ofcom, "Ofcom's approach to net neutrality" (24 November 2011), [1.7]. Available at http://stakeholders.ofcom.org.uk/consultations/net-neutrality/statement/ (accessed 12 Aug 16).
}

\footnotetext{
${ }^{46}$ Council of Europe, Declaration of the Committee of Ministers on network neutrality (29 September
} 2010), [4]. Available at https://wcd.coe.int/ViewDoc.jsp?id=1678287 (accessed 12 Aug 16). 
cybercrime. ${ }^{47}$.. exceptions to this principle should be considered with great circumspection and need to be justified by overriding public interests. ${ }^{48}$

As well as the Council of Europe declaration, there were developments at the EU level. Two communications from the Commission opened up debate and consultation on EU policy for net neutrality. In April 2011, a communication from the Commission to Parliament and the Council entitled The Open Internet and Net Neutrality in Europe, ${ }^{49}$ noted that despite Art. 8(4)(g) of the Framework Directive ${ }^{50}$ requiring national regulatory authorities to promote the interests of the citizens of the European Union by promoting the ability of end-users to access and distribute information or run applications and services of their choice, concerns had been raised about throttling of peer-to-peer (P2P) file-sharing or video streaming by certain providers in France, Greece, Hungary, Lithuania, Poland, and the United Kingdom and blocking or charging extra for the provision of voice over Internet Protocol (VoIP) services in mobile networks by certain mobile operators in Austria, Germany, Italy, the Netherlands, Portugal, and Romania. ${ }^{51}$ The Commission noted that the EU remained committed to "preserving the open and neutral character of the internet, taking full account of the will of the co-legislators now to enshrine net neutrality as a policy objective and regulatory principle to be promoted by national regulatory authorities". ${ }^{52}$ The Commission also noted though that amendments made in the 2009 Telecoms Reform Package were still being implemented by member states and so recommended no immediate action be taken, rather they would monitor the situation.

The monitoring period ended in summer 2012. A study by the Body of European Regulators of European Communications (BEREC) found that $20 \%$ of all Internet users, and potentially up to half of EU mobile broadband users, had contracts that allowed their ISP to restrict services like VoIP or P2P. They further found that those fixed and mobile operators with contractual restrictions on P2P, 96\% of fixed line providers and $88 \%$ of mobile providers, enforced them technically. ${ }^{53}$ As a result, the Commission launched a public consultation into transparency, switching, and Internet traffic management with the aim of preserving net neutrality. The public consultation stage closed on 15 October 2012, after which the Commission put together a series of packages on net neutrality and mobile roaming which led to the publication of the Connected Continent legislation package on 11 September 2013. ${ }^{54}$ Key amongst this package was the proposal for a Regulation laying down measures concerning the European single market for electronic communications and to achieve a Connected

\footnotetext{
${ }^{47}$ Ibid, 5.

${ }^{48}$ Ibid, 6.

${ }^{49} \operatorname{COM}(2011) 222$ final.

${ }^{50}$ Dir. 2002/21/EC.

${ }^{51}$ See note 49 above, 4.1 .

${ }^{52}$ EU telecoms reform package [2009] OJ L 337.

${ }^{53}$ BEREC, A View of Traffic Management and other Practices Resulting in Restrictions to the Open Internet in Europe (29 May 2012). Available at http://ec.europa.eu/digital-agenda/sites/digitalagenda/files/Traffic\%20Management\%20Investigation\%20BEREC 2.pdf (accessed 12 Aug 16).
}

${ }^{54}$ Available at http://ec.europa.eu/digital-agenda/en/node/67489/\#open internet (accessed 12 Aug 16). 
Continent (the Telecoms Regulation). ${ }^{55}$ Although the proposed Regulation covered a lot of ground, including co-ordination of the Radio Spectrum market and mobile roaming agreements, it also provided for net neutrality through a number of provisions but primarily through chapter IV (Arts.21-29). As was noted in the explanatory notes to the draft:

The obligation on providers to provide unhindered connection to all content, applications or services being accessed by end-users - also referred to as Net Neutrality - while regulating the use of traffic management measures by operators in respect of general internet access. At the same time, the legal framework for specialised services with enhanced quality is clarified. ${ }^{56}$

Unfortunately, in a series of tripartite negotiations between the Commission, the Council and the Parliament, these strong Net Neutrality provisions were sacrificed in order to gain agreement on other aspects of the Regulation. After receiving a strong endorsement by the Parliament at first Reading in April 2014, an agreement was reached with the Parliament on 9 July 2014. It was sent to the Council for agreement, and there it hit a hurdle. It was reported in March 2015 that the Council proposed an alternative set of net neutrality rules which "would establish a principle of "net neutrality' but still allow telecoms groups to manage the flow of Internet traffic to ensure the network worked efficiently. They will also be able to agree deals with corporate and individual customers to provide faster Internet services - although the proposals make clear that these would not be allowed to impair the wider working of the Internet in any 'material manner"', in essence a two-speed Internet. ${ }^{57}$

The final version of the Regulation as passed on 25 November $2015^{58}$ gives support for only one aspect of net neutrality as explained by the second Recital: "The measures provided for in this Regulation respect the principle of technological neutrality, that is to say they neither impose nor discriminate in favour of the use of a particular type of technology." The net neutrality provisions have been removed in favour of provisions technological neutrality, transparency and market regulation. The key provisions are now found in Arts. 3-5 and allied regulations. Article 3 pronounces that open Internet access safeguards ensure technological neutrality:

End-users shall have the right to access and distribute information and content, use and provide applications and services, and use terminal equipment of their choice, irrespective of the end-user's or provider's location or the location, origin or destination of the information, content, application or service, via their internet access service.

Note that there is no QoS requirement, although it may be argued that Art. 1(3) does appear to provide some form of net neutrality protection: "Providers of internet access services shall treat all traffic equally, when providing internet access services, without

\footnotetext{
${ }^{55} \operatorname{COM}(2013) 627$ final. Available at https://ec.europa.eu/digital-agenda/news-redirect/11950 (accessed 12 Aug 16).

56 Ibid, 12.

57 D Thomas, D Crow and D Robinson, "Proposals on European net neutrality open 'two-speed' internet" Financial Times (London, 3 March 2015) available at www.ft.com/cms/s/0/5688747c-c19211e4-bd24-00144feab7de.html (accessed 12 Aug 16).

${ }^{58}$ Reg. 2015/2120.
} 
discrimination, restriction or interference, and irrespective of the sender and receiver, the content accessed or distributed, the applications or services used or provided, or the terminal equipment used."

This, however, is undermined by both Arts. 1(2): "Agreements between providers of internet access services and end-users on commercial and technical conditions and the characteristics of internet access services such as price, data volumes or speed, and any commercial practices conducted by providers of internet access services, shall not limit the exercise of the rights of end-users laid down in paragraph 1"; and the second part of 1(3):

the first subparagraph shall not prevent providers of internet access services from implementing reasonable traffic management measures. In order to be deemed to be reasonable, such measures shall be transparent, nondiscriminatory and proportionate, and shall not be based on commercial considerations but on objectively different technical quality of service requirements of specific categories of traffic. Such measures shall not monitor the specific content and shall not be maintained for longer than necessary.

To ensure these provisions are not abused, there are the transparency requirements of Art. 4 including that:

providers of internet access services shall ensure that any contract which includes internet access services specifies at least the following: (a) information on how traffic management measures applied by that provider could impact on the quality of the internet access services, on the privacy of end-users and on the protection of their personal data and (b) a clear and comprehensible explanation as to how any volume limitation, speed and other quality of service parameters may in practice have an impact on internet access services, and in particular on the use of content, applications and services.

The idea here is that the market and consumer choice will play a major role in ensuring no abuse occurs. To this end, BEREC were tasked to produce draft guidelines to National Regulatory Authorities designed to ensure "compliance with the rules to safeguard equal and non-discriminatory treatment of traffic in the provision of internet access services and related end-users rights." BEREC opened the draft guidelines to consultation and it has been reported that they have received in excess of 500,000 consumer responses to them. ${ }^{59}$ In addition, both Arts. $3 \& 4$ are backed up by the requirement that national regulatory authorities monitor service providers for compliance with the Regulation and the requirement of an annual report to BEREC. ${ }^{60}$ The final regulation, and the draft guidelines, have both been the subject of extensive criticism ${ }^{61}$ and there are early indicators that some service providers are

\footnotetext{
${ }^{59}$ European Communications (Press Release), "500,000 have final say on EU net neutrality laws" (25 July 2016). Available at http://www.eurocomms.com/industry-news/11704-500-000-have-final-say-oneu-net-neutrality-laws (accessed 12 Aug 16).

${ }^{60}$ Art 5(1).

61 A Hern, "EU net neutrality laws fatally undermined by loopholes, critics say" The Guardian (London, 27 October 2015). Available at http://www.theguardian.com/technology/2015/oct/27/eu-netneutrality-laws-fatally-undermined-by-loopholes-critics-say (accessed 12 Aug 16); G Smith, "This is what the EU thinks is "net neutrality" Fortune (New York, 27 October 2015). Available at http://fortune.com/2015/10/27/this-is-what-the-e-u-thinks-is-net-neutrality/ (accessed $12 \mathrm{Aug} 16$ ).
} 
seeing this as a green light to introduce tiered services, ${ }^{62}$ a position that has come under criticism from, among others, Sir Tim Berners-Lee and Professor Lawrence Lessig. ${ }^{63}$

This leaves two questions: why did the Council insist on those changes to the Regulation, and where will this leave net neutrality in Europe? The answer to the first is unclear. The Council likes to talk of the concept of remote medical care and even remote surgery where a surgeon in Frankfurt could carry out surgery remotely via the Internet in Bad Kissengen. This they suggest will only be possible if the surgeon can be assured of a high quality differentiated network connection. It is more likely, though, that pressure from major network operators, and the need to broker a deal on data roaming, were really behind the position of the Council. Where will this leave net neutrality in Europe? The short answer is exactly where it was before. A failure to enshrine net neutrality does not mean it goes away; it simply means that it is not enshrined by law. In the short term nothing will change, but over time network operators may, emboldened by the stops take in Council, apply more traffic controls and access controls, perhaps leading to a two-speed Internet. The timing of the Council intervention could not be worse, given the moves of the FCC to ensure net neutrality in the United States. Though, as we have seen, they too are likely to come under threat via the action of the petition of the USTA.

It may be argued that the institutionalist approach has failed to adequately protect net neutrality. The US command and control approach has been struck down again and again by the courts as being ultra vires and it is likely that the United States Telecom Association v FCC \& Ors application will lead to the same outcome once more. ${ }^{64}$ The command and control approach used by the FCC has become a game of regulatory whack-a-mole. The FCC passes a Rule or Order and the telecommunications companies challenge it. It seems clear that despite the efforts of the FCC to mandate network neutrality in the United States that there have been repeated violations of the principle including Comcast's BitTorrent block, ${ }^{65}$ AT\&T's Face Time block ${ }^{66}$ and Verizon's block on tethering apps. ${ }^{67}$ In fact, according to one report in the one month after the 2015 Rules took effect the FCC received around 2,000 consumer complaints around a number of net neutrality issues including slow speeds, high prices, and data caps. ${ }^{68}$ In the same period, European regulators have mostly relied upon competition

\footnotetext{
${ }^{62}$ T Höttges, "Net neutrality: Finding consensus in the minefield" Deutsche Telekom Blog (Bonn, 28 October 2015) available at http://www.telekom.com/media/management-to-the-point/291728 (accessed 12 Aug 16).

${ }^{63}$ Web Foundation, "Four Days to Save the Open Internet in Europe: An Open Letter" (14 July 2016). Available at http://webfoundation.org/2016/07/four-days-to-save-the-open-internet-in-europe-an-openletter/ (accessed 12 Aug 16).

${ }^{64}$ See notes 36 and 38 above.

${ }^{65}$ Comcast Corp. v FCC, see note 16 above.

${ }^{66}$ FCC Mobile Broadband Working Group, AT\&T/FaceTime Case Study (20 August 2013). Available at https://transition.fcc.gov/cgb/oiac/Mobile-Broadband-FaceTime.pdf (accessed 12 Aug 16).

${ }^{67}$ FCC, 'Verizon Wireless To Pay \$1.25 Million To Settle Investigation' (31 July 2012). Available at https://apps.fcc.gov/edocs_public/attachmatch/DOC-315501A1.pdf (accessed 12 Aug 16).

${ }^{68}$ J Brodkin, "FCC has already gotten 2,000 'net neutrality' complaints", Ars Technica (San Francisco, 30 July 2015). Available at http://arstechnica.com/tech-policy/2015/07/net-neutrality-complaints-targetspeeds-prices-and-data-caps/ (accessed 12 Aug 16).
} 
regulation, but as the BEREC report demonstrates, this is not working: $20 \%$ of all Internet users in the period in question, and potentially up to half of EU mobile broadband users, had contracts that allowed their ISP to restrict services like VoIP or $\mathrm{P} 2 \mathrm{P}$. Of those fixed and mobile operators with contractual restrictions on P2P, 96\% of fixed line providers and $88 \%$ of mobile providers enforced them technically. ${ }^{69}$ The failure of the institutionalist approach suggests that instead of continuing to play this narrow and failing game, regulators should reconsider how best to regulate for net neutrality. In the next section, we propose an alternative: a principled approach.

\section{A Principled Approach}

In his seminal book, Code, and Other Laws of Cyberspace ${ }^{70}$ Lawrence Lessig argues that code, as the architecture of the Internet, is the most powerful regulator of activity within cyberspace. His theory centres on the idea that Internet users are regulated by four constraints: law, social norms, the market, and architecture $^{71}$ Of those, architecture, according to Lessig, is most able to control users' behaviour, and their experience of the Internet. Lessig even asserts that "[t]he code embeds certain values or makes certain values impossible". ${ }^{72}$ As such, the design of the Internet's code can be changed to further a certain vision of what we believe the Internet's purpose should be.

Part of this code includes the way data is transmitted over the network. As has been seen, the network was originally designed around the "end-to-end principle", whereby bits of information are transported between intelligent terminals through dumb pipes. ${ }^{73}$ Less metaphorically, this means that ISPs, as providers of the network, have no knowledge of the content of the data they are transferring, this content being decipherable only by its sender and receiver. The end-to-end principle has long been held as guarantor of an open Internet, and as conducive to a competitive market for Internet content, relying on the possibility of anyone to be an innovator. When broadband Internet arrived on the US market in the early 2000s, Lemley and Lessig identified the ability of cable companies to bundle ISP service as a threat to the principle of end-to-end, in that the control over innovation would shift from a variety of users and programmers to a single network owner. ${ }^{74}$

Through the evolution of technology, and justified by the need to rationalise the exponential increase in data transfers, ISPs have developed traffic management practices, whereby they are able to inspect the content of the data they are transporting, in order to assign to it a certain transfer speed or priority over other types of data. These practices exemplify how the architecture of the Internet can control the digital environment: by exercising control over the speed at which data is transferred, ISPs influence the user's experience of the Internet. This is the current threat to the

\footnotetext{
${ }^{69}$ See note 53 above.

${ }^{70}$ L Lessig, Code and Other Laws of Cyberspace (New York: Basic Books, 1999).

${ }^{71}$ L Lessig, Code Version 2.0 (New York: Basic Books, 2006), at 123.

72 Ibid, 125.

${ }^{73}$ See note 37 above and related text.

${ }^{74}$ M Lemley \& L Lessig, "The End of End-to-End: Preserving the Architecture of the Internet in the Broadband Era" (2001), 48 UCLA Law Review 925-972, at 942.
} 
end-to-end principle that the Internet must tackle. As previously discussed, it has been found for example that ISPs in Austria, Germany, Italy, the Netherlands, Portugal, and Romania blocked or charged extra costs for the provision of voice-over internet protocol (VoIP) services in mobile networks while ISPs in France, Greece, Hungary, Lithuania, Poland, and the United Kingdom were found to be throttling of P2P filesharing or video streaming. ${ }^{75}$ This is a clear instance of control by ISPs over the use we make of the Internet and our experience of it. ISPs may control behaviour in response to law to a further extent than the law intends. In Ireland, the largest ISP, Eircom, includes in its terms of use for broadband users a policy on offensive speech: "Customers may not use the Facility to create, host or transmit offensive or obscene material, or engage in activities, which are likely to cause offence to others on any grounds including, but not limited to race, creed, or sex."76 This language goes beyond the words of s. 2(1) of the Prohibition of Incitement to Hatred Act 1989, which makes it an offence to utter or publish statements that "are threatening, abusive or insulting and are intended or, having regard to all the circumstances, are likely to stir up hatred." Eircom, through these terms of use, is thus creating a new standard of offensive speech in cyberspace, unique to its customers. ${ }^{77}$

\section{1. The Value of a Neutral Internet}

This kind of code design has crucial implications for individual rights. In order to carry out their traffic management practices, ISPs rely on Deep Packet Inspection (DPI) - the detailed examination of the contents of the data being transferred. This examination of what users send through the network has the potential to impede individuals' rights to privacy and freedom of expression, and to distort fair competition by prioritising certain types of communications.

These activities are threats to the fundamental value of the network. The importance of the Internet today is such that it may be classified as a public good. As the IFLA argues in its Trend Report, "in a context where Internet access is swiftly becoming an indispensable economic and social enabler within a modern hyper-connected world, without Internet access it becomes increasingly challenging to take full advantage of existing human rights". ${ }^{78}$ Indeed, the Internet creates a huge and diverse community that provides its members with an open platform to inform and express themselves, communicate, exchange, organise and grow social movements, and more generally allow them to "engage on equal footing in economic, social and political activities."79 It has become a fundamental element of democratic participation. An unprecedented number of people are able to access the Internet, which provides them with a discourse platform with a reach much more extensive than that offered by traditional

\footnotetext{
${ }^{75}$ See note 49 above and related text.

${ }^{76}$ Available at https://www.eir.ie/opencms/export/.content/pdf/terms/Part3.1.pdf (accessed 12 Aug 16).

${ }^{77}$ D Mac Sitigh, "Regulating the Medium: Reactions to Network Neutrality in the European Union and Canada" (2011) 14 Journal of Internet Law 3-14.

78 IFLA, IFLA Trend Report Expert Meeting (Mexico City, 4-5 March 2013), 10. Available at http://trends.ifla.org/files/trends/assets/ifla-trend-report-expert_meeting_synthesis_2013-04-26.pdf (accessed 12 Aug 16).

${ }^{79}$ Council of Europe, Steering Committee on Media and Information Society (CDMSI), "Protecting Human Rights through Network Neutrality: Furthering Internet Users' Interest, Modernising Human Rights and Safeguarding the Open Internet”, December 2013, 5.
} 
media. Not only does the Internet provide easy and free access to information sources, it also allows people to contribute to debates in a way not possible before: "With the removal of spatial and temporal bounds, and the freedom to participate anonymously or pseudonymously, the internet facilitates town-hall type gatherings and the creation of communities that might not otherwise have formed." 80 Allowing everyone to vote is not enough for democracy to be realised - individuals must have the opportunity to voice their opinions, put them up to challenge by others, and exchange ideas. And the less costly it is to do so in terms of time and resources, the better it is. The Internet provides for that, and in addition is an indispensable vector of participation in more routine, yet still crucial, activities. One needs only think of the amount of daily transactions and personal business or social activities we carry out through the Internet. Almost all dealings with our banks, telephone companies, electricity and gas providers, gyms, universities, etc., are made online. Without an Internet connection, we are automatically shut off from easy, streamlined access to these essential services.

Historically, the Internet was regarded simply as a new communications medium, prone to influence by market forces and profit considerations. Even today, some still take this view, and advocate for leaving it to the hands of commercial entities to define its place in our society. ${ }^{81}$ But the Internet has such an important role for all modern individuals that it should be considered essential for the protection of human rights, and access to it should be treated as a public good: it serves functions from which no one should be excluded, and whose consumption by one person should not reduce consumption by another. ${ }^{82}$ The problem is that ISPs, the providers of access to the Internet, are commercial entities pursuing the maximisation of their profits, and so are not concerned about the provision of unfiltered and diverse information. ${ }^{83}$ When ISPs "manage traffic" on the Internet, they "only do so in properly utilitarian manner for their benefit" - their priority is to utilise their network in the most efficient way, without regard to welfare and humanitarian concerns. ${ }^{84}$ And because they are not public bodies, they are not subject to the same standards of human rights protection than public bodies. ${ }^{85}$ In most countries, private actors are not subject to obligations to protect human rights - in the UK for example, the Human Rights Act 1998 explicitly provides that only public bodies are bound by the Act and expected to respect its provisions. ${ }^{86} \mathrm{We}$ can thus only rely on governments to police the behaviour of private entities. Emily Laidlaw explains the dangerous importance of "privately owned internet information gatekeepers (IIGs)" - of which ISPs are an important type - in facilitating the internet's democratic potential.

The role of such regulators has not yet been settled, and, as of yet, they do not have any democratic or public interest mandate that assures the Internet's democratic potential is being facilitated. If the Internet is a democratising

\footnotetext{
${ }^{80}$ Laidlaw, see note 1 above, at 15.

${ }^{81}$ See A Renda, “Antitrust, Regulation and the Neutrality,” CEPS Special Report, No. 104 (April 2015).

${ }^{82}$ G Adamson, “Internet Futures: A Public Good or Profit Centre?”, (2002) 11 Science as Culture $257-$ 275 .

${ }^{83}$ Council of Europe, see note 79 above, at 23.

${ }^{84}$ Marsden, see note 10 above, at 12.

${ }^{85}$ Council of Europe, see note 79 above, at 18.

${ }^{86}$ Human Rights Act 1998, s 6.
} 
force, we inevitably at present must rely on these IIGs for the realisation of this aspect of its capacity. ${ }^{87}$

Thus, in order to preserve the Internet's openness and to expand its access, regulations should be enacted to prevent ISPs from carrying out illegitimate discrimination of certain types of data. These regulations should pursue the goal of net neutrality, a fundamental principle of an open Internet, according to which "data packets on the Internet should be moved impartially, without regard to content, destination or source" ${ }^{88}$ The Council of Europe recognises net neutrality as a "key enabler of human rights", 89 noting that "both net neutrality and openness facilitate inclusion, transparency, fair competition and non-discrimination with the goal of fostering participation, cooperative creativity and the full enjoyment of human rights". 90 Indeed, net neutrality furthers the "edges-empowering" character of the Internet, placing the end users in control of their communications, which allows them to send and access whatever kind of content they wish, without fear of an undesirable third party scrutinising their activities. We now turn to an assessment of how net neutrality preserves the Internet's capacity to foster participative democracy by protecting privacy and freedom of expression. We will also see that net neutrality is crucial to protect innovation and competition.

\section{2. Net Neutrality and Privacy}

Net neutrality is necessary for the protection of privacy rights. Enshrined by Article 8 of the European Convention of Human Rights (ECHR), the right to respect for private and family life establishes that "[e]veryone has the right to respect for his private and family life, his home and his correspondence." Traffic management and QoS practices will apply deep packet inspection which seeks to "read" some content information. Based upon this "reading" content may be blocked, throttled, or used for profiling. Whatever the purpose, the fundamental problem lies in the fact that if ISPs apply these kinds of policies, personal and even confidential information may be interrogated by the ISPs applying QoS principles. This conflicts with the right to confidentiality of communications, ${ }^{91}$ and with "the right to respect for...private and family life... and correspondence." 92 The Council of Europe draws a useful analogy with the traditional postal services to illustrate how pervasive such an inspection is: it would undoubtedly seem unacceptable if a mailman was able to open every letter he had to carry, and, based on their content, decide at what speed these would reach their recipient, or even which of these would simply not get there. ${ }^{93}$ One would feel deeply violated if private communications were scrutinised in this fashion, and so in the same

\footnotetext{
${ }^{87}$ Laidlaw, see note 1 above, 2.

${ }^{88}$ Murray, see note 8 above.

${ }^{89}$ Council of Europe, see note 79 above, at 5 .

${ }^{90}$ Ibid, 10.

91 European Data Protection Supervisor (EDPS), Opinion of the EDPS on net neutrality, traffic management and the protection of privacy and personal data (Brussels, October 7, 2011), 11.

${ }^{92}$ European Convention on Human Rights, Art 8.

${ }^{93}$ Council of Europe, see note 79 above, at 19.
} 
way, deep packet inspection for reasons other than avoiding congestion on the network is an infringement on privacy.

Koops and Slujis evaluated the extent to which ISPs' traffic management practices could be an infringement of Article $8 .{ }^{94}$ After recognising that "[i]f DPI is used and thus correspondence is intercepted by the ISP, there is a clear interference with users' right to privacy", ${ }^{95}$ they conclude from their analysis that a finding of violation of Article 8 will be very rare, and will depend on "the kind of traffic that is managed and the reasons for this; the duration and scope of network management;... and the extent to which public authorities have been involved". ${ }^{96}$ They notably argue that Article 8 will be violated only when traffic management takes the form of blocking, or when degrading or prioritising traffic is based on sender or recipient information. The thing is, these do happen. Governments and courts already order the blocking of a number of pornographic and file-sharing websites ${ }^{97}$ - this requires ISPs to be able to identify who attempts to access those websites and to impede them from doing so. Moreover, ISPs' discrimination practices hinder the use of encrypted browsing, which "prevents internet providers from injecting ads into the pages you view and prevents them from logging your activities to sell to marketers...Without net neutrality, there's no telling what privacy-enabling tools will become unusable at the whim of internet providers." 98

It may be argued that traffic management methods can be used by ISPs without inspecting the content of communications, rather only inspecting the type of material carried. Such a method would use the IPv6 header to signify whether the packet should get priority treatment, without reading the content itself. Saying that this would not violate privacy because it does not access any information transmitted by users is a misconception. When Paul Ohm suggests "Net non-scrutiny" as an alternative to Net neutrality, which would allow ISPs to look at the TCP port numbers on packets but not to carry out deep packet inspection, he argues that "scrutiny without handling does not violate Net neutrality and handling without scrutiny does not necessarily implicate privacy". ${ }^{99}$ This relies on only one aspect of privacy, focused on privacy of communications. One should consider privacy more broadly, as the ability to access any content with an assured transmission speed, that does not vary according to

\footnotetext{
${ }^{94}$ B-J Koops \& JP Slujis, "Network Neutrality and Privacy According to Art. 8 ECHR", 3(2) European Journal for Law and Technology (2012) available at http://ejlt.org/article/view/90/233 (accessed 12 $\underline{\text { Aug 16). }}$

95 Ibid, 5.

96 Ibid, 13.

97 On the Comcast affair : P Eckersley, F von Lohmann \& S Schoen, "Packet Forgery By ISPs: A Report On The Comcast Affair", Electronic Frontier Foundation, Version 1 (28 November 2007). On various filtering and blocking orders by the UK government: E Johnson-Williams, "A Quick Guide to Cameron's Default Internet Filters," Open Rights Group (30 July 2013) available at https://www.openrightsgroup.org/blog/2013/a-quick-guide-to-camerons-default-internet-filters (accessed 12 Aug 16).

${ }^{98}$ A Glaser, "An Open Internet is Essential to a Free Internet: Why Net Neutrality Should Matter to Everyone" (Electronic Frontier Foundation, 10 September 2014) available at https://www.eff.org/deeplinks/2014/09/open-internet-essential-free-internet-why-net-neutrality-shouldmatter-everyone (12 Aug 16).

99 P Ohm, "When Network Neutrality Met Privacy" (April 2010) 53(4) Communications of the Association for Computing Machinery 30-32.
} 
whether the user is reading an online newspaper or streaming videos. Affording priority to certain types of content has a pervasive influence on one's freedom to choose the type of material one wishes to consult on the Internet.

This question of privacy is becoming increasingly topical, as the Investigatory Powers Bill comes closer to enactment. If passed, the Bill would grant powers of mass surveillance by authorising bulk interception of communications. Without a strong commitment to net neutrality enshrined in legislation, the Bill will grant such powers without any technical constraint on the ability to snoop into individual communications - widespread interception and examination of content will be made much easier by the lack of neutrality in ISPs' practices. Net neutrality is thus necessary to protect basic principles of privacy, and to ensure that technology is not an aid to unacceptable intrusion into citizens' communications.

\section{3. Net Neutrality and Freedom of Expression}

Net neutrality plays an equally important role in protecting freedom of expression. Article 10 of the ECHR ensures the right "to receive and impart ideas and information without interference". The Internet today is possibly the most important platform for expression, imposing no technical restriction on what people can say, and allowing for wide-reaching dissemination of opinions and debate. As the Council of Europe observes, "[i]n our current information society, the ability to freely receive and impart ideas and information and to fully participate in the democratic life is truly reliant on the nature of one's Internet connection". ${ }^{100}$ While it may be contended that an Internet connection is not mandatory to "impart ideas and information", today it is undoubtedly the most efficient medium. Before we could make use of the Internet, public discussions were held physically, in town halls or public squares. The people who made the effort to come down there were very engaged and politically conscious people, or maybe frustrated citizens who wished to voice their anger. Political debates were mainly held on TV or on the radio, gathering politicians and public figures, but rarely ordinary citizens. Today, the Internet allows anyone with a connection to participate in such discussions and debates in real time. This is a formidable evolution towards a more inclusive and participative democracy. The Internet also affords its users a freedom to participate in an unrestricted fashion. Thanks to the anonymity and pseudonymity offered online, and thanks to an open design where censure is hard to execute, people are free to engage in open debates where all opinions are pitted against each other in an unrestricted marketplace of ideas where discourse can elevate knowledge and reasoning. This open design also creates the opportunity to challenge harmful opinions to show their flaws, rather than outright banning them from expression and letting them retrench in dark corners where they can grow and reinforce each other around hatred.

Having a neutral Internet, where ISPs cannot inspect the content of communications and speech, prevents a strong chilling effect on speech coming from people knowing they are constantly watched and monitored. Al Franken has called net neutrality the "free speech issue of our time", because he believes that "the Internet is the public

\footnotetext{
${ }^{100}$ Council of Europe, see note 79 above, at 6.
} 
square of the $21^{\text {st }}$ century." 101 Similarly, Brown and Marsden point out that "traffic management techniques affect not only high speed, high money content but, by extension, all other content too." 102 As the most important communication platform, the Internet requires the most extensive efforts be put in to protect freedom of expression. And ISPs, as providers of access to this platform, should not be able to use techniques to encroach on freedom of speech. Regulators have a responsibility to provide and secure access to such a platform to enable people to realise their free speech rights. As Marvin Ammori argued in his seminal article "First Amendment Architecture", realising the aim of the First Amendment requires more than "negative liberty", whereby the government refrains from any involvement in speech. Under negative liberty, government cannot ensure access to digital spaces because it would be making decisions about who can speak that should be left to the private market. ${ }^{103}$ This is a fundamental misconception about the nature of the right to freedom of expression. In order to be enjoyed freely by all, this right requires more than a lack of interference in people's exercise of it - it requires the development and maintaining of an "architecture" designed to provide spaces for this exercise. If we leave it to ISPs and private entities to decide what kind of content can and cannot be delivered, or who will have easy and streamlined access to platforms of expression and who will not, we effectively shut out a proportion of the population from access to necessary spaces for expression. The government is thus required to positively act, through net neutrality regulation, to ensure these spaces exist and are open to everyone, in the same way.

Beyond the issue of the provision of free speech architecture, we must see that by preventing certain services and information to be diffused to Internet users, traffic management techniques such as filtering and blocking have a feel of censorship. Mac Sithigh gives the example of when the pro-choice group NARAL was refused permission to use a "short code" SMS facility provided by large carrier Verizon in the U.S., to illustrate "the dangers of allowing unregulated service providers to pick and choose between content providers, thus regulating, in practice, not just the communicative rights of the provider but the actual content received by the consumer." ${ }^{104}$ Although the NARAL dispute only concerns a refusal to issue a short code and thus does not touch upon differential treatment network traffic, it efficiently illustrates both the capacity and willingness of telecoms service providers to refuse access to the network as it suits them, without any legal basis. Already highly controversial on its own, censorship becomes even more controversial when it is effected by private actors, here ISPs. Marsden shows that Deep Packet Inspection is

\footnotetext{
101 A Franken, "Net Neutrality vote will be a win for free speech", (MashableUK, 25 February 2015) available at http://mashable.com/2015/02/25/al-franken-net-neutrality/\#FWo981VeBkqL (accessed 12 Aug 16).

102 I Brown and C Marsden, Regulating Code: Good Governance and Better Regulation in the Information Age (Cambridge: MIT Press, 2013), 142.

${ }^{103}$ See for a discussion of negative liberty and free speech: M Ammori, "Digital Spaces and the Future of Free Speech" (Huffington Post US, 28 May 2011) available at http://www.huffingtonpost.com/marvin-ammori/digital-spaces-and-the-fu_b_841408.html (accessed 12 Aug 16).

${ }^{104}$ D Mac Sitigh, see note 77 above, at 2. See also A Liptak, "Verizon Rejects Text Messages from an Abortion Rights Group", New York Times, Sept. 27, 2007.
} 
increasingly used both by Western ISPs and in countries with more autocratic governments. It happens through co-regulation:

The government sets the rules and the ISPs are allowed a broad measure of independence as to process to achieve the results the government sets out. This is controversial in that it passes powers to control freedom of expression into private hands, often without the constitutional protections that govern public authority intervention and censorship ${ }^{105}$

It is crucial to strip ISPs of their ability to discriminate and censor, so that such a dangerous power is not exercised by non-accountable actors.

Just as with privacy, the importance of protecting freedom of expression through net neutrality is highly topical when one considers the imminent enactment of the Investigatory Powers Bill. In an era of mass surveillance, where intelligence agencies have widespread power and legitimacy to watch and monitor everyone's communications and activities on the Internet, ISPs being co-opted by the government to maintain a backdoor into these communications is highly dangerous. Leaving ISPs the ability to inspect content maintains this backdoor. The chilling effect on speech in this instance is even stronger: knowing one's communications are watched by law enforcers makes people highly reticent to share "unconventional" or "inconvenient" opinions, out of fear of ending up on the records of "people to watch". This is exacerbated in countries with autocratic governments, where safeguards against arbitrary law enforcement may not be as strong.

In comparison, a non-neutral Internet can be an Internet of censure, where scrutiny of speech and communications would chill the expression of contentious views, thereby excluding minority views and reinforcing majority opinion. ${ }^{106}$ Net neutrality thus enables freedom of expression by removing barriers to the transmission of communications and by making it impossible for "inconvenient" opinions to be arbitrarily censored, or unexpressed in the first place. ${ }^{107}$

\section{4. Net Neutrality, Innovation and Competition}

Net neutrality also has a vital role to play in innovation and fair competition, and of freedom to conduct business, as enshrined in Article 16 of the EU Charter of Fundamental Rights. ${ }^{108}$ The market for Internet content promotes creative innovation by imposing low barriers to entry. This is thanks in great part to the end-to-end architecture of the Internet, which creates "an infrastructure fundamentally open to the creative contributions of a multitude of innovators, be they hardware designers, network operators, application creators, or content authors."109 However, traffic management practices raise these barriers by making it harder for new entrant content creators to distribute the product of their work at an acceptable level of quality.

\footnotetext{
105 Marsden, see note 10 above, at 19.

${ }^{106}$ E Stoycheff, “Under Surveillance: Examining Facebook's Spiral of Silence Effects in the Wake of NSA Internet Monitoring” (2015) Journalism \& Mass Communication Quarterly 1.

107 Council of Europe, see note 79 above, at 17-18.

${ }^{108}$ Charter of Fundamental Rights of the European Union, 2000/C 364/01.

109 F Bar, W Baer, S Ghandeharizadeh, and F Ordononez, "Infrastructure: Network Neutrality and Network Futures" in K Varnelis (ed), Networked Publics (Cambridge: MIT Press 2008), 111.
} 
Practices such as preferential agreements, whereby ISPs reserve specific portions of bandwidth to certain content providers to provide better quality service, harm content providers that do not have the means to pay for such agreements, thereby discouraging innovation and indirectly harming consumers. ${ }^{110}$

In 2014, the largest US cable and broadband provider, Comcast, entered into an agreement with Netflix whereby Netflix would pay Comcast for faster and more reliable access to Comcast's subscribers. ${ }^{111}$ The agreement was justified by the fact that Netflix traffic uses a particularly high amount of the network's capacity, and so it should be asked to pay for its content to get to customers in a reliable way. Fair enough - Netflix has the necessary size and revenue to be able to pay for this, and Comcast subscribers will be happy to use Netflix at high speed. The problem is that this is profoundly detrimental for competition amongst content providers. By establishing that content providers are able to pay ISPs - probably a lot of money - to afford better transmission to their content, this effectively gives an enormous advantage to established players on the market which have the means to pay these sums. In the end, this prevents smaller, new entrants on the market from competing with the big ones. Cooper and Brown argue that "discrimination generally reduces application developers' incentives to innovate because it vests the control over which applications succeed or fail in the hands of network operators". ${ }^{112}$ This discrimination leaves them "at the mercy of infrastructure owners, forcing them into business arrangements that would restrict their options." 113 It has been argued by ISPs that preferential agreements are what users want, since it would allow for more reliable transmission speeds in accessing high-volume content. But content providers who cannot pay the kind of money that Netflix paid to Comcast, such as start-ups, will get stuck in the slow lane. ${ }^{114}$ While a more reliable connection is undeniably desirable for the content's users, it should not come at the expense of access to future innovation and exploration of "evolutionary paths". One should also not forget that if content providers are charged for accessing the network's fast lane, consumers are the ones who will foot the bill. This may be acceptable to the ISP's customers who use the content in question, but it is not acceptable to make consumers who subscribe to other ISPs, or who may want to use another content provider, to pay for this.

Preserving the end-to-end architecture of the Internet is thus crucial to promote innovation and to leave doors open to the next generation of content providers. As Lessig explained seventeen years ago, "[t]his end-to-end design frees innovation from

\footnotetext{
110 The authors acknowledge the distinction between interconnection disputes and true net neutrality disputes. However as argued by Timothy Lee in his essay Beyond Net Neutrality: The new battle for the future of the internet, we argue that interconnection disputes have the capacity to affect users in an equal manner to net neutrality and should be treated as equivalent in their effects. See T. Lee, Beyond Net Neutrality (Vox, November 12 2014). Available at http://www.vox.com/2014/5/2/5665890/beyondnet-neutrality-the-new-battle-for-the-future-of-the-internet (accessed 12 Aug 16).

${ }^{111}$ E Wyatt and N Cohen, "Comcast and Netflix Reach Deal on Service" (The New York Times, 23 February 2014) available at http://www.nytimes.com/2014/02/24/business/media/comcast-and-netflixreach-a-streaming-agreement.html?_r=0 (accessed 12 Aug 16).

${ }^{112}$ A Cooper and I Brown, "Net Neutrality: Discrimination, Competition, and Innovation in the UK and US,” (February 2015) 15(1) ACM Transactions on Internet Technology, Article 2.

${ }^{113}$ Bar et al, see note 109 above, at 112.

${ }^{114}$ Franken, see note 101 above.
} 
the past. It's an architecture that makes it hard for a legacy business to control how the market will evolve." 115 This is the reason why Franken argues that net neutrality is "what prevents deep-pocketed corporations from buying an unfair advantage over new competitors." 116

As we have already shown, some mobile ISPs use traffic management to reduce the quality of VoIP services, which directly compete with their telephony services. ${ }^{117}$ VoIP users typically pay much lower charges per minute, and are therefore "much less profitable than dedicated phone subscribers". ${ }^{118}$ This is highly disruptive of fair competition in the Internet content market. It renders VoIP services unusable or less reliable in the eyes of consumers, denying them access to novel services which could make their lives better. While Renda argues that ISPs' position on the market has been hurt by services such as Skype or WhatsApp, and thus that they should be allowed to compensate by charging more for better service quality, ${ }^{119}$ he overlooks the fact that Skype and WhatsApp rely upon high network quality and so are highly dependent on ISPs' services, while mobile network operators do not depend on them for their telephony services. It is true that these services use up an important share of bandwidth, yet it should not be their role to contribute to ISPs' necessary investments in expanding the network. If Virgin or BT need to develop their infrastructure further, to provide better network access, it should be on them; not on content developers whose concern should be creating new innovative services, and nothing else. Each player in the market should concern itself about improving its own services, not about trying to find someone to blame for the need to improve these services. Again, putting responsibility on content developers to contribute to investments in infrastructure, by asking them to pay for a reliable transmission of their services, will inevitably lead to a fundamentally unfair advantage given to big, rich content providers. Although the amount of throttling of VoIP services has certainly reduced since BEREC revealed these practices, they represent a worrying willingness by ISPs to discriminate or deprioritise certain services for their own commercial advantage, and measures should be taken to ensure that ISPs do not have the power to repeat this in the future.

The last issue we ought to deal with is that of zero-rating, a practice by ISPs which consists in excluding preferred content from data caps, so that downloading costs amount to zero in consumers' bills. ${ }^{120}$ Content providers and ISPs enter into an agreement, whereby content providers pay ISPs to make their content available to the ISP's consumers at no cost. An example of this practice is Facebook's FreeBasics (originally Internet.org), a walled garden which includes only a handful of websites, not the whole Internet, and which is intended to "provide people with access to useful services on their mobile phones in markets where internet access may be less affordable". ${ }^{121}$ FreeBasics was recently banned in India following powerful

\footnotetext{
115 L Lessig, “Architecting Innovation”, The Industry Standard (14 November 1999).

${ }^{116}$ Franken, see note 101 above.

117 See note 49 above and related text.

${ }^{118}$ Marsden, see note 10 above, at 15.

${ }^{119}$ Renda, see note 81 above, at 6.

${ }^{120} \mathrm{C}$ Marsden, "Comparative Case Studies in Implementing Net Neutrality: A Critical Analysis of Zero Rating” (2016) 13 SCRIPTed 1, 7.
}

${ }^{121}$ Available at https://info.internet.org/en/story/free-basics-from-internet-org/ (accessed 12 Aug 16). 
mobilisation by civil society against what was deemed a threat to net neutrality. Indeed, FreeBasics effectively allowed Facebook to monopolise a system of information by retaining the power to decide what services Indian consumers could have access to. Zero-rating has been banned in various other countries, such as Canada, Brazil or Slovenia ${ }^{122}$, as it constitutes an important threat to fair competition and innovation, and to net neutrality. As Tim $\mathrm{Wu}$ has argued, the fact that content creators do not have to pay anything in order to make their content available to users' ISPs facilitates their entry on the market, and promotes a wide array of choice for consumers. ${ }^{123}$ If we allowed ISPs to charge content providers, this would lead to what Wu calls "fragmentation", whereby certain content would only be available through certain ISPs, thus creating "multiple Internets". ${ }^{124}$ The "[p]otential welfare losses could also be significant as consumers would find themselves foreclosed from accessing content available only on rival service providers, and content providers would find themselves unable to reach certain segments of the population captive to service providers with whom no agreement had been reached"125 Zero-rating is thus a practice that runs counter to an open and neutral Internet.

The challenge that these various practices pose to the end-to-end architecture and to innovation on the Internet was identified and explained by Mark Lemley and Lawrence Lessig fifteen years ago, when unfair practices by network owners first arose:

An architecture that maximizes the opportunity for innovation maximizes innovation. An architecture that creates powerful strategic actors with control over the network and what can connect to it threatens innovation. No doubt these strategic actors might choose to behave in a procompetitive manner. There is no guarantee that they will interfere to stifle innovation. But without competition or regulation to restrict them, we should not assume that they will somehow decide to act in the public interest. $^{126}$

The threat to innovation that Lessig identified has in those past fifteen years been pushed back by efforts to keep net neutrality alive on the Internet. But it is coming back today, and it is bigger than ever, reinforced by arguments about the need to expand the network. Net neutrality-enforcing regulation is thus necessary to level the playing field, not simply for reasons of fairness to new entrants, but most importantly for consumer and citizen welfare around the world.

\section{The Importance of the Principled Approach}

Having established that network neutrality is necessary for a rights-friendly, open and innovative network, it remains to be shown that regulation through mandated network neutrality provisions is required to protect this principle. Research findings show that

\footnotetext{
${ }^{122}$ Marsden, see note 120 above.

${ }^{123} \mathrm{~T}$ Wu, "Subsidizing Creativity through Network Design: Zero-Pricing and Net Neutrality" (2009) 23 Journal of Economic Perspectives 3.

${ }^{124}$ Ibid, 7.

$125 \mathrm{Ibid}, 8$.

${ }^{126}$ Lemley and Lessig, see note 74 above, at 938.
} 
ISPs do currently carry out traffic management and blocking practices that are detrimental to many kinds of services. The threat to network neutrality is thus real, and something has to be done about it. Hahn and Wallsten, in an article positioned against net neutrality, argue that competition law and antitrust enforcement are sufficient to promote innovation and ensure fair practices. ${ }^{127}$ But that is simply not true. Arguing so relies on the premise that consumers will merely choose the ISP that carries out the least discrimination. This is overly simplistic. It further assumes full capacity of consumers to, first, realise and understand the implications of discrimination practices, and second, switch ISPs at no cost and with ease. But consumers have much less agency capacity than that, and most do not care as much about non-discrimination as lawyers do. Cooper and Brown show that "'in practice, most consumers have difficulty finding and understanding traffic management disclosures", ${ }^{128}$ and that the role of traffic management in switching decisions is secondary. It is thus crucial, in order to protect fundamental rights and promote innovation, to recognise positive obligations on governments to protect network neutrality, and to enact specific legislation to that effect.

It is important that new legislation does not repeat the mistakes of institutionalist command and control or market regulation. Legislation and regulation in this field must be based upon rights-based principles of privacy, freedom of expression and the freedom to conduct business. We must stop imagining the Internet as a communications media and start to see it for what it truly is: a common good, or rather common space, which is at the heart of our modern democratic society. The right to network neutrality should be seen as just that, a right based on its fundamental role in supporting and delivering other fundamental rights. Network neutrality should only be restrictable on the grounds set out in the fundamental rights framework not for commercial grounds or for QoS principles. That is not to say ISPs and other network providers should not be able to charge more to make use of their network with excess profits raised being reinvested in building network capacity. We must acknowledge that technologies such as VoD streaming and VoIP have put extreme strain on overall network capacity. What cannot be allowed, on the principled approach, is the treatment of some forms of data being different to other forms of data.

The Internet is a powerful enabler of social and economic integration, almost indispensable in order to carry out some of the most basic activities in our contemporary digitised world. The benefits people derive from using the Internet result from its open architecture, its easiness of access, and the plurality of content it provides. These characteristics of the Internet should thus be protected through the positive promotion of network neutrality. Counting on market competition to keep ISPs' practices in line is simply unrealistic, which is why mandated network neutrality provisions are necessary. Although "the Internet thrives on lack of regulation", ${ }^{129}$ regulating net neutrality is one of the rare instances of government intervention that promotes, rather than impedes, freedom and innovation, freedom of expression and possibly also online privacy.

\footnotetext{
${ }^{127}$ R Hahn and S Wallsten, “The Economics of Net Neutrality” (2006) 3 The Economists'Voice 1.

${ }^{128}$ See note 112 above, at 3 .

${ }^{129}$ Federal Communications Commission, see note 15 above.
} 